\title{
O DEBATE DERIVA/CONTATO NA HISTÓRIA DO PORTUGUÊS BRASILEIRO
}

\author{
Janderson LEMOS DE SOUZA*
}

- RESUMO: Este artigo retoma o debate acerca da prevalência do fator deriva, considerado como estritamente interno, ou do fator contato, considerado como estritamente externo, na constituição do português brasileiro. No plano empírico, a retomada privilegia o contato com línguas do ramo banto. No plano teórico, circunscreve-se em bases epistemológicas da linguística cognitiva, em que se discute a adequação de dois desdobramentos: uma linguística cognitiva de contato e uma sociolinguística cognitiva. $\mathrm{O}$ artigo recapitula a associação entre contato e crioulização, tendo em vista dissociar os dois fenômenos; rejeita a tese de que o contato se restringe à influência lexical, tendo em vista associar a dicotomia deriva/contato à dicotomia léxico/gramática; e propõe uma hipótese do contato baseada em processos de domínio geral. Reformular o debate nestes termos permite concluir que o contato motiva compatibilizações entre conceptualizações, por se tratar de cognições em contato, e não de línguas em contato.

- PALAVRAS-CHAVE: Linguística Cognitiva. Linguística Cognitiva de Contato. Sociolinguística Cognitiva. Contato. Deriva. Relativismo. História do Português Brasileiro.

\section{Introdução}

$\mathrm{O}$ contato entre o português e línguas do ramo banto da família níger-congo (NURSE; PHILIPPSON, 2003; LUCCHESI, 2004), como constitutivo do português brasileiro, tem atraído o interesse de linguistas e historiadores (FIORIN; PETTER, 2008; ALMEIDA, 2014, 2019; AVELAR; GALVES, 2014; NEGRÃO; VIOTTI, 2014; MAGALHÃES, 2018; AVELAR, 2019). Dentre as línguas que pertencem ao ramo, apenas algumas eram faladas pelos povos deslocados ao Brasil na condição de escravos (ALMEIDA, 2014, 2019; LUCCHESI, 2004; PESSOA DE CASTRO, 2012), o que impõe o cuidado de identificar quais línguas bantas entraram em contato com aquela versão do português ao longo de três séculos em diversos pontos do que depois veio a ser o território brasileiro: o quicongo, quimbundo e o umbundo. ${ }^{1}$

\footnotetext{
Universidade Federal de São Paulo (UNIFESP), Escola de Filosofia, Letras e Ciências Humanas (EFLCH), São Paulo - SP - Brasil. Professor. ORCID: https://orcid.org/0000-0002-4252-7789. janderson.souza@unifesp.br.

1 A recorrente menção a essas três línguas remete à relevância estatística, mas o número de línguas faladas pelos povos escravizados é impossível rastrear (OLIVEIRA; LOBO, 2009).
} 
O interesse se insere numa longa agenda de discussão sobre o português brasileiro ser como é por evolução natural do português europeu ou por contato com línguas indígenas e africanas.

Calcula-se que, quando da chegada dos portugueses ao Brasil, aproximadamente 1.175 línguas (RODRIGUES, 1993) seriam faladas pela população indígena. Embora tenham aportado no Brasil em 1500, o início do processo de transplantação da sua língua ocorrerá, sensivelmente, a partir da década de 1530, quando o rei D. João III por isso mesmo chamado de o colonizador - traça, com a divisão do país em Capitanias Hereditárias, uma política para povoar e administrar as novas terras. Também na década de 1530, dá-se início ao tráfico de escravos que para aqui trará falantes de, aproximadamente, 200 a 300 línguas (PETTER, 2006).

Passados, hoje, mais de 500 anos de muitas e diversas histórias de contato lingüístico, não há língua africana sendo falada como nativa por nenhuma comunidade lingüística brasileira, sobrevivem cerca de 150 a 180 línguas indígenas, faladas por uma população de aproximadamente 260.000 índios, e é a esmagadora maioria da população brasileira falante nativa de uma língua que é continuadora histórica da língua portuguesa e a que a lingüística brasileira contemporânea tem designado de português brasileiro. (OLIVEIRA; LOBO, 2009, p. 7)

Portanto, abordar o contato com as línguas bantas pode ser feito ab ovo (contemplando os muitos e vastos estudos sobre a história e os igualmente muitos e vastos estudos sobre os contatos) ou in medias res (conciliando o fenômeno histórico contato com um quadro teórico). A segunda opção é a escolhida neste artigo, em que resgato o debate deriva/contato para abordá-lo de acordo com fundamentos da linguística cognitiva, em linha com estudos recentes que desenvolvem uma linguística cognitiva de contato (ZENNER, 2013; NOËL, 2015; ZENNER; BACKUS; WINTER-FROEMEL, 2018).

O debate se tornou clássico nos estudos sobre a história do português brasileiro: a configuração da língua portuguesa em sua variedade brasileira se deve a "[...] um processo natural de evolução pelo qual mecanismos internos à língua motivam algumas mudanças; ou uma ruptura do processo natural, ocasionada pelo contato de uma língua com outras línguas" (NEGRÃO; VIOTTI, 2012, p. 315)? Costuma ser associado a questões como o que é, afinal, português brasileiro; a língua ser brasileira, e não portuguesa; a homogeneização de variedades internas ao português brasileiro pelo adjetivo "brasileiro" tal qual a homogeneização de variedades internas ao português europeu pelo adjetivo "europeu", homogeneizações que colocariam em xeque rótulos como PB e PE; as relações entre variação e mudança; entre outras que remetem a uma vasta bibliografia. 
Portanto, este artigo não se dedica ao reexame da história do português brasileiro em suas marcas distintivas das do português europeu ou qualquer outra variedade. Dedicase ao reexame de posições teóricas a respeito da história do português brasileiro, tendo em vista formular uma nova posição pró-contato, que, baseada em fundamentos da linguística cognitiva, dissolve a dicotomia entre deriva e contato e privilegia processos cognitivos de domínio geral.

\section{Fundamentos e procedimentos no caminho do debate}

O primeiro fundamento da linguística cognitiva que invoco é o relativismo. Com isso, acabo entrecruzando um debate com outro: deriva $v s$ contato e universalismo $v s$ relativismo.

Um debate, na interface entre a linguística e a história, faz parte da agenda dos estudiosos da história da língua portuguesa, língua que estabeleceu contato com línguas indígenas e africanas. Dentre diversos temas, os estudiosos de línguas indígenas tendem a enfatizar que o Brasil jamais foi um país monolíngue - ponto em que a distinção entre língua oficial e língua natural é crucial - e a destacar as línguas indígenas em risco de extinção, com vistas a uma política linguística que preserve tais línguas. Eis uma agenda de pesquisa. Já os estudiosos de línguas africanas, em geral, e bantas, em particular, assumem o desafio de identificar quais línguas do ramo entraram em contato com o português de então, que seria europeu no Brasil, não ainda brasileiro pois anterior ao contato nem europeu tal qual em Portugal, num esforço de periodização e categorização que costuma gerar controvérsia. Eis outra agenda de pesquisa.

O outro debate, na interface entre a linguística e a filosofia [da linguagem] (MARTINS, 2011), diz respeito à relação entre linguagem e pensamento. Seria o pensamento livre da linguagem ou constituído pela linguagem? Grosso modo, a tese universalista é que há o pensar, que pode ou não ser acrescido da linguagem para fins de expressão, enquanto a tese relativista é que a linguagem é constitutiva do pensar, ou seja, que não há o pensar tão-somente, e sim o pensar numa língua natural.

Langacker (1994) entende que a questão por trás das teses pode ser formulada equivocadamente se se confundir o fato de existirem as diferentes palavras "língua", "pensamento", "cultura" e "cognição" com o fato de corresponderem a fenômenos apartados, e não sobrepostos, além de não ser empírica. Eis a representação do entendimento rejeitado pelo autor (Figura 1.a) e do entendimento defendido pelo autor (Figura 1.b): 
Figura 1 - Relativismo na gramática cognitiva

(a)

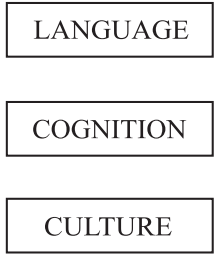

(b)

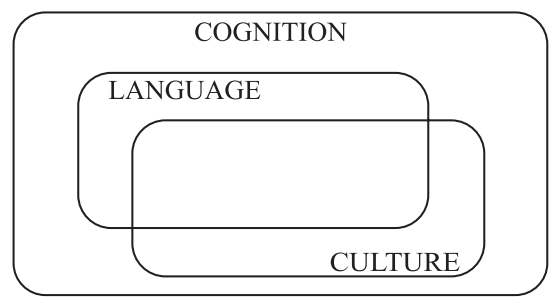

Fonte: Langacker (1994, p. 26).

Com base nesta versão de relativismo, atribuo parte da controvérsia envolvida no debate deriva/contato à concepção que restringe o fenômeno a línguas. Nesta concepção, existem aspectos da linguagem que são culturais e aspectos que não são, porém os aspectos que não têm origem cultural não estão isentos de manifestação cultural. O caráter enciclopédico do significado, um fundamento da linguística cognitiva, resulta exatamente da sobreposição entre língua e cultura como facetas da cognição num dos seus modelos, intitulado gramática cognitiva (LANGACKER, 1987, 1994, 2008, 2009).

Em outro modelo, a gramática das construções cognitiva, Lakoff (1987, p. 334-335, tradução nossa) adota uma versão mais difundida de relativismo:

Sou eu um relativista? Bem, eu adoto visões que caracterizam uma das milhares de formas de relativismo.

Como linguista, estou interessado na gramática das línguas, especialmente em que conceitos estão gramaticizados nas línguas do mundo e que conceitos não estão. Também estou interessado no que significa um conceito estar gramaticizado, e é aí que surge a questão do uso. Whorf estava certo ao observar que conceitos que se tornaram parte da gramática de uma língua são usados no pensamento, não apenas como objetos do pensamento, e que são usados espontaneamente, automaticamente, inconscientemente e sem esforço. Como cientista da cognição, estou interessado não somente em quais são nossos conceitos mas também em como eles são usados. ${ }^{2}$

\footnotetext{
2 Original: "Am I a relativist? Well, I hold views that characterize one of the hundreds of forms of relativism. [...] As a linguist, I am interested in the grammar of languages, especially in what concepts are grammaticized in the languages of the world and what concepts are not. I am also interested in what it means for a concept to be grammaticized, and it is here that the use issue arises. Whorf was right in observing that concepts that have been made part of the grammar of a language are used in thought, not just as objects of thought, and that they are used spontaneously, automatically, unconsciously, and effortlessly. As a cognitive scientist, I am interested not only in what our concepts are but also in how they are used" (LAKOFF, 1987, p. 334-335).
} 
Tal concepção de relativismo remete à inspiração wittgensteiniana da linguística cognitiva, outro ponto controverso que caracteriza outra agenda de investigação. Limitome a rastrear a origem da posição adotada pela linguística cognitiva, sem discutir o grau de fidelidade da teoria a Wittgenstein (LAKOFF, 1987; MARTINS, 1999). A inspiração aqui se localiza na concepção de uma língua natural como evidência de uma forma de vida:

No que diz respeito às práticas lingüísticas, Wittgenstein não adota um naturalismo determinista, mas antes um relativismo cultural (por exemplo, MS109 58), que decorre do relativismo conceitual presente na idéia da AUtonomia DA LinguAGEM. Nega-se, em tal relativismo conceitual, apenas a idéia de que nossas formas de representação estejam sujeitas a padrões metafísicos, a uma pretensa essência da realidade, mas não que possam sujeitar-se a padrões pragmáticos. Entretanto, esse relativismo se baseia na idéia de que cada forma de representação estabelece seus próprios padrões de racionalidade, o que implica que até mesmo as justificações pragmáticas são inerentes aos jogos de linguagem particulares. (GLOCK, 1998, p. 175-176).

Trata-se, portanto, de uma versão do relativismo que "[...] enfatiza [...] o entrelaçamento entre cultura, visão de mundo e linguagem" (GLOCK, 1998, p. 173-174).

A versão de relativismo adotada pela gramática cognitiva e a versão adotada pela gramática das construções cognitiva compartilham a concepção da cognição como situada, o que estabelece, na linguística cognitiva, a relação entre uma racionalidade inscrita na gramática de uma língua e a perspectiva com que os falantes de uma língua concebem o mundo:

A perspectiva, especialmente a dêixis, talvez seja a mais óbvia e mais comentada das operações que influem no construal. Particularmente para descrições espaciais, a perspectiva é essencial, e sua dependência à posição relativa e ao ponto de vista do falante é bem conhecida. Mas a perspectiva também se encontra em domínios não espaciais: temos uma perspectiva baseada em nosso conhecimento, crença e atitudes tanto quanto em nossa posição espaço-temporal. A propriedade cognitiva mais próxima à perspectiva tomada em sentido amplo é provavelmente a noção filosófica de nossa situacionalidade no mundo numa posição particular - em que posição deve ser considerada em sentido amplo para incluir o contexto temporal, epistêmico e cultural, além de espacial. ${ }^{3}$ (CROFT; CRUSE, 2004, p. 58, grifo do autor, tradução nossa).

\footnotetext{
Original: "Perspective, especially deixis, is perhaps the most obvious and most commented upon of the construal operations. Particularly for spatial descriptions, perspective is essential, and its dependence on the relative position and viewpoint of the speaker is well known. But perspective is also found in nonspatial domains: we have a perspective
} 
Portanto, assumir “[...] que o significado é perspectivista (não reflecte objectivamente o mundo, mas modela-o, constrói-o de determinada maneira ou perspectiva e, assim, de muitas perspectivas diferentes) [...]" (SOARES DA SILVA, 2006, p. 7) pressupõe o caráter situado da cognição, que, por sua vez, se associa ao caráter distribuído da cognição, pois "[...] é importante realçar a agência dos indivíduos no processo como um todo" (NEGRÃO; VIOTTI, 2012, p. 316). A situacionalidade e a distribuição da cognição dos que falam português brasileiro embutem, por conseguinte, crenças e atitudes daqueles falantes daquelas línguas bantas nesta interseção entre o debate deriva/contato e o debate universalismo/relativismo, dada a tensão entre o universal e o relativo: "Se a língua tanto molda quanto reflete a experiência humana, então a língua é tão histórica quanto tal experiência: enquanto parte da experiência humana é universal e biologicamente específica da espécie, outra parte é histórica e cultural"4 (GEERAERTS, 2011, p. 333, tradução nossa).

Em se tratando de um artigo dedicado a refletir sobre a configuração do português brasileiro a partir do contato com algumas das línguas bantas, o desempate quanto ao primeiro debate resultaria a favor do contato. Em se tratando de um artigo também comprometido com os fundamentos da linguística cognitiva, o desempate quanto ao segundo debate resultaria a favor do relativismo.

Como esses são pontos de partida, seria esperado operar com base neles, empreender uma descrição de algum aspecto do português brasileiro a partir do contato e pelo viés relativista. Este artigo, no entanto, se dispõe a discutir os termos em que esses pontos de partida devem ser formulados. No que tange ao primeiro debate, o objetivo é dissolver a dicotomia deriva/contato. No que tange ao segundo, o objetivo é propor que se deixe de pensar em línguas em contato e se passe a pensar em cognições em contato.

\section{Deriva vs contato, léxico vs gramática, social vs estrutural}

Avelar e Galves (2014, p. 242-243) apontam o tom dicotômico com que o debate deriva/contato se apresenta:

Os debates em torno dessa questão têm se dado de forma polarizada, com defensores do que podemos chamar de hipótese da deriva e hipótese do contato ocupando cada um dos lados da polarização - os primeiros argumentam em favor de que todas as marcas gramaticais do português brasileiro foram trazidas de Portugal, não havendo nenhuma propriedade

based on our knowledge, belief and attitudes as well as our spatiotemporal location. The closest cognitive property to perspective taken broadly is probably the philosophical notion of our situatedness in the world in a particular location - where location must be construed broadly to include temporal, epistemic and cultural context as well as spatial location" (CROFT; CRUSE, 2004, p. 58).

4 Original: "If language both shapes and reflects human experience, then language is as historical as that experience: while part of the human experience is universal and biologically species-specific, another part is historical and cultural" (GEERAERTS, 2011, p. 333). 
inovadora devida à ação de contatos interlinguísticos; os segundos defendem que o português brasileiro apresenta características gramaticais que emergiram como consequência do contato, em particular no que diz respeito à constituição das suas variedades populares.

Mantida a polarização, este artigo se filiaria à hipótese do contato, tendo em vista opor-se à hipótese da deriva, segundo a qual "[...] no português do Brasil inexiste influência gramatical específica de qualquer língua africana" (NARO; SCHERRE, 2007, p. 182) .

Em outras palavras, para Naro e Scherre, as características do português brasileiro contemporâneo são desenvolvimentos naturais do português arcaico e clássico. Por isso, elas não podem nem devem ser explicadas como fruto do contato do português com as línguas indígenas do Brasil ou com as línguas trazidas pelos escravos africanos, nem como o resultado de um processo de transmissão imperfeita no processo de aquisição de língua. Embora os autores admitam a importância do contato com os povos africanos e indígenas na constituição da cultura brasileira, seu entendimento parece ser o de que três séculos de multilinguismo não impactaram sobremaneira a formação da gramática da língua falada hoje no Brasil. (NEGRÃO; VIOTTI, 2012, p. 320).

Entretanto, mais que adotar uma ou outra hipótese, convém ao quadro teórico aqui adotado a dissolução da polarização, que emerge junto com outras num cenário que cumpre recuperar. O resultado pretendido é uma hipótese do contato em que o contato determine o curso da deriva. Para isso, recuperemos a história dos conceitos envolvidos.

Câmara Jr. (1986, p.113-114) atribui o termo deriva a Sapir, tendo em vista o caráter teleológico do termo evolução:

EVOLUÇÃO - Conjunto de mudanças que sofre uma língua em sua história interna. O nome foi adotado nos meados do séc. XIX, a exemplo das ciências naturais, onde "evolução" significa o crescimento gradual e paulatino de um organismo até atingir a plenitude. Muitos lingüistas rejeitam ou pelo menos evitam o termo, porque na língua não há a rigor um crescimento, mas apenas mudanças e, muito menos, a marcha para a plenitude.

Tal posição já se encontra em nossa tradição lexicológica: “[...] o empréstimo, embora compreendido em têrmos de tão larga dimensão, só se observa, em rigor, nos domínios do léxico ou do vocabulário. Com efeito, parece não haver línguas que recebam de outras caracteres do sistema fonológico ou morfológico" (CARDOSO; CUNHA, 1978, p. 138). 
Neste sentido lingüístico, particular, a evolução se opõe ao empréstimo, que é uma mudança proveniente da adoção de elementos provenientes de outra língua distinta.

$[\ldots]$

Em lugar do termo, Sapir lançou outro - DERIVA (ing. drift), que assinala apenas o encadeamento das mudanças numa direção nítida (Sapir, 1954, 165). (CÂMARA JR., 1986, p.113-114)

Na definição acima, pode-se identificar:

(i) a oposição entre o fator interno e o fator externo de desencadeamento da mudança, oposição que leva a crer que os fatores não podem coexistir e que, prevalecendo o externo, sua incidência se restringe ao léxico, por sua vez, concebido como apartado da gramática;

(ii) a presença de um autor que marcou a história da linguística como defensor da tese relativista, Edward Sapir, o que, por si só, torna a tese pró-deriva compatível com o relativismo, fundamento adotado tanto por teorias reconhecidas pelas continuidades quanto por teorias reconhecidas pelas rupturas (linguística estruturalista, linguística funcional e linguística cognitiva). ${ }^{6}$

Câmara Jr. (1986, p. 126) associa o conceito evolução ao conceito gênio da língua em termos relativistas:

GÊNIO DA LÍNGUA - Maneira tradicional (cf. Leoni, 1858) de designar os caracteres gerais da gramática (v.) de uma língua nas suas oposições formais e funcionais (v. função). Do ponto de vista diacrônico, referese a um sentido geral da evolução (v.), a que Sapir denominou DERIVA (Sapir, 1954).

Tal conceito reaparece na definição de vocábulo: “É - como diz Sapir - 'uma forma que chama a si grande ou pequena parte do pensamento integral na medida em que o gênio da língua se compraz em o permitir' (Sapir, 1921, 33)" (CÂMARA Jr., 1989, p. 93). ${ }^{7}$

6 Em Lemos de Souza (2016), enfatizo que continuidades e descontinuidades epistemológicas devem ser consideradas tanto nos fundamentos quanto nos procedimentos. A reconhecida afinidade entre a linguística funcional e a linguística cognitiva, por exemplo, se confirma na adoção da tese pró-relativismo como fundamento mas não se converte em consenso quanto ao papel do contato. Por outro lado, a reconhecida oposição entre a linguística gerativa e a linguística cognitiva em todos os fundamentos não impede o consenso quanto ao papel do contato, como se verá adiante.

7 Devo dizer que a formulação em Sapir (1921, p. 33) é ligeiramente diferente: "The word is merely a form, a definitely molded entity that takes in as much or as little of the conceptual material of the whole thought as the genius of the language cares to allow." 
Resgatado o caráter relativista do conceito de deriva, explica-se a adequação da posição de Naro e Scherre (2007) a esse fundamento adotado pela linguística funcional. No entanto, influem no debate deriva/contato outros dois quadros teóricos: a sociolinguística e a linguística gerativa.

Pagotto (2007) situa o debate deriva/contato num momento dos estudos da história do português brasileiro em que o estrutural era contrastado com o social, sendo o estrutural do interesse da linguística gerativa, que se pautava pela teoria da regência e ligação (GALVES, 1995), e o social do interesse da sociolinguística, que se pautava pela teoria da variação e da mudança (WEINRICH; LABOV; HERZOG, 1968). A circunstância da ciência forjou as feições do objeto, de tal modo que não se percebeu que o que já estava em jogo era:

a) em primeiro plano, o contraste entre dois modelos de categorização - o aristotélico, adotado pela linguística gerativa, e o radial (para o qual Labov contribuiu enormemente), adotado pela linguística funcional e pela linguística cognitiva:

Muito do trabalho por parte da psicóloga Eleanor Rosch sobre categorias naturais (2) sugere uma semântica baseada em protótipo. Para o ponto que estou levantando, a 'naturalidade' das categorias não é tanto a questão, mas ajuda. A noção da semântica baseada em protótipo que tenho em mente é esta: posso conhecer um quadrado mais ou menos diretamente; um trapezoide, no entanto, conheço, à primeira vista pelo menos, como um quadrado que foi distorcido de uma forma específica.

Relacionado a essas questões está o que alguns pesquisadores veem como o problema de determinar fronteiras entre categorias linguísticas. Esse expediente é exemplificado em alguns estudos recentes de William Labov (3). Conhecer a categoria xícara (como oposta a copo ou jarra) é reconhecer propriedades como a proporção entre a circunferência da abertura e a altura do recipiente, ter uma alça, ser feito de material vítreo opaco, ser usado para consumo de alimento líquido, ser acompanhado de um pires, afinar e ser circular em seção transversal. ${ }^{8}$ (FILLMORE, 1977, p. 56, tradução nossa).

\footnotetext{
Original: "Much of the work on the part of the psychologist Eleanor Rosch on natural categories (2) suggests a prototype semantics. For the point I am making, the 'naturalness' of the categories is not so much the issue; but that helps. The prototype semantic notion I have in mind is this: I can know a square more or less directly; a trapezoid I know, however, in the first instance anyway, as a square that got distorted in a particular way. Related to these questions is what some researchers see as the problem of determining linguistic category boundaries. This work is exemplified in some recent studies of William Labov's (3). Knowing the category cup (as opposed to glass or bowl) is recognizing such properties as the ratio between the circumference of the opening and the height of the container, having one handle, being made of opaque vitreous material, being used for consumption of liquid food, being accompanied with a saucer, tapering, and being circular in cross-section". (FILLMORE, 1977, p. 56). As notas (2) e (3) correspondem, respectivamente, a "ROSCH, E., 'Natural categories', Cognitive Psychology 4, (1973), pp. 328-350" e "LABOV, W., 'The boundaries of words and their meanings', in C-J; N. BAILEY and R. SHUY, (eds.), New Ways of Analyzing Variation in English, Georgetown University Press, 1973".
} 
b) Em segundo plano, o contraste entre dois modelos de cognição - o modular, adotado pela linguística gerativa, e o conexionista, adotado pela linguística funcional e pela linguística cognitiva:

Ao contrário do paradigma simbólico, que (...) concebe o processamento cognitivo como cadeias de representações simbólicas que são manipuladas linearmente, o paradigma conexionista postula que o processamento cognitivo se baseia em complexos de unidades ou nós conectados em redes dinâmicas em que umas unidades excitam ou inibem outras. (FRANÇA; FERRARI; MAIA, 2016, p. 179).

Em outras palavras, o rótulo sociolinguística sobressaiu à proposta de um modelo de categorização. Esse acidente na história da linguística fez parecer que a variação é um fenômeno social quando nasceu exatamente caracterizado como cognitivo manifestado socialmente, assim como impediu de perceber que a suposta oposição entre o estrutural e o social é a versão simplificada e distorcida da oposição entre cognição descorporificada e categorização aristotélica, de um lado, e cognição corporificada e categorização radial, de outro.

A “[...] fundamentação [da sociolinguística cognitiva] no enquadramento teórico da Linguística Cognitiva [...]" (SOARES DA SILVA, 2009, p. 192) parece poder colaborar com a superação de tal acidente ao "[...] mostrar como intrinsecamente se relacionam as dimensões cognitiva e social da linguagem [...]" (SOARES DA SILVA, 2009, p. 192), ressalvado o projeto da própria linguística cognitiva como linguística sociocognitiva (ALMEIDA, 2005; SALOMÃO, 2009). O que insisto em resgatar é que, a despeito do adjetivo que acompanhe "sociolinguística", o compromisso com o modelo radial de categorização é constitutivo, o que torna equivocada a recepção que levou a separar o social e o estrutural.

Graças a tal acidente, não se costuma atentar para o caráter cognitivo do debate em sua origem. A primazia da deriva implicaria que "[...] o português brasileiro seria apenas a continuação natural e gradual do processo de mudança que é comum a todas as línguas indo-européias e que no caso do português encontra eco nas perdas morfológicas do latim" (PAGOTTO, 2007, p. 462-463). Sendo assim, faria sentido discutir a origem crioula do português brasileiro dentro dos limites da pidginização, crioulização e dialetação.

A crioulização apontaria para a distância entre o português brasileiro e o europeu, enquanto a descrioulização para a proximidade. Ser ou não um crioulo estaria associado a ter ou não sofrido influência das línguas com que teve contato. Daí os defensores da deriva assumirem que o contato gera apenas empréstimos, não chega ao nível estrutural, o que, portanto, descarta a crioulização e implica que a história do português brasileiro o afasta do português europeu, mas não por influência do contato: "[...] o contato do português com diversas línguas teria propiciado o surgimento de uma variedade dialetal, não um crioulo" (PAGOTTO, 2007, p. 465). 
[...] todas as vezes que se descarta a hipótese de origem crioula para o português do Brasil, descarta-se, por tabela, o papel que o contato interlingüístico teria tido na sua constituição. É por esta razão que penso ser mais interessante deixar a questão viva, como um incômodo latente, uma farpa lá no fundo da carne, para que os estudos de natureza puramente lingüística não dominem exclusivamente a cena. $\mathrm{Ou}$, dizendo de outra maneira, sem o contato interlingüístico no Brasil Colônia e no Brasil Império, o português brasileiro não teria as características que teria hoje. Esta última formulação traz para o plano central o papel que ameríndios e africanos tiveram no processo de formação do português do Brasil, sem que caiamos na armadilha de supô-lo todo como fruto de um único pidgin e/ou uma única língua crioula. (PAGOTTO, 2007, p. 467-468).

Considero a proposta de não permitir que "estudos de natureza puramente linguística" dominem a cena como convite a contemplar estudos de natureza histórica (SLENES, 1992, 1995, 2018; ALMEIDA, 2014, 2019). Reconhecer que "o português brasileiro não teria as características que tem hoje" torna, para os objetivos deste artigo, inevitável retomar o debate deriva/contato, não pela substituição da hipótese da deriva pela hipótese do contato, mas por:

(i) recuperar do conceito de deriva sua afinidade original ao relativismo, de modo a esclarecer por que a hipótese da deriva teve lugar na linguística funcional;

(ii) identificar a entrada do fator crioulização no debate como alheio aos fundamentos das teorias envolvidas mas concernente ao procedimento de separar entre história interna e história externa;

(iii) harmonizar a deriva assim concebida e o contato assim concebido com a concepção de língua e cultura como facetas da cognição; e

(iv) entender e superar o equívoco de opor o social e o estrutural, seja por meio de uma linguística cognitiva de contato, seja por meio de uma sociolinguística cognitiva, seja pela própria recuperação do vínculo original entre sociolinguística e modelo radial de categorização.

Cada um desses passos incidentais mereceria um artigo. $\mathrm{O}$ passo que mais pode contribuir aos objetivos deste artigo permite descartar a crioulização sem descartar o papel do contato, nos termos de Pagotto (2007) acima. A linha de estudos que rejeita a dicotomia entre história interna e história externa (NEGRÃO; VIOTTI, 2012, 2014; VIOTTI, 2013) se harmoniza com a linha de estudos que nega à crioulização o status de fenômeno linguístico (MUFWENE, 2000, 2007, 2010, 2015).

Mufwene (2015) inclui em sua rejeição à crioulização como fenômeno linguístico a rejeição à categorização radial de propriedades que caracterizariam crioulos, exatamente 
aquelas levadas em conta pelos que defendiam a hipótese do contato com base na crioulização. Obviamente, rejeitar o fenômeno pressupõe rejeitar qualquer que seja a abordagem ao fenômeno.

Por caminhos diferentes, este artigo converge com a posição do autor: para ele, o que a literatura convencionou chamar crioulização não é um fenômeno linguístico; neste artigo, mesmo assumindo que a crioulização fosse um fenômeno linguístico, ser um processo de domínio específico o tornaria menos capaz de explicar um processo superveniente como a mudança linguística por contato. A conclusão é: contato sim, crioulo não.

Os processos de domínio geral que a gramática cognitiva propõe são: associação, automatização, esquematização e categorização (LANGACKER, 2008). O único processo de domínio geral proposto pela gramática das construções cognitiva é a categorização (LAKOFF, 1987). O detalhamento de cada um fugiria aos objetivos deste artigo, em que invoco os fundamentos da linguística cognitiva para fomentar uma linguística cognitiva de contato capaz de formular uma hipótese do contato sem a polarização apontada por Avelar e Galves (2014) e sem a associação à crioulização apontada por Pagotto (2007).

\section{Hipótese do contato: nova afinidade entre universalistas e relativistas}

Um número significativo de trabalhos tem procurado demonstrar que algumas propriedades sintáticas do português brasileiro (FIORIN; PETTER, 2008; OLIVEIRA; LOBO, 2009; OLIVEIRA; SOLEDADE; SANTOS, 2009; AVELAR; GALVES, 2014; AVELAR, 2019), inclusive as que mais surpreendem quanto ao comportamento argumental, como o deslocamento à esquerda, já se encontram nas línguas bantas faladas pelos escravos trazidos ao Brasil.

A propósito, o deslocamento à esquerda no quimbundo já interessava a Givón (2001) como origem da construção passiva na mesma língua, de modo a caracterizar sua proposta de abordagem funcional à língua e abordagem tipológica à gramática:

\section{Deslocamento à esquerda mais 'eles' impessoal}

Finalmente, em algumas línguas, como o quimbundo, uma construção passiva se desenvolveu diacronicamente de, e ainda se assemelha estruturalmente $\mathrm{a}$, uma construção de deslocamento à esquerda mais o pronome impessoal ‘eles', como em (Givón 1995: cap. 3):

\section{a. Passiva}

Nzua a-mu-mono kwa meme

João eles-o-viram por mim

'João foi visto por mim'

(lit.: 'João, eles o viram por mim') 


\section{b. Deslocamento à esquerda \\ Nzua, aana a-mu-mono \\ João crianças eles-o-viram \\ 'João, as crianças o viram'}

c. Sujeito impessoal com deslocamento à esquerda

Nzua, a-mu-mono

João eles-o-viu

'João, eles o viu' (anafórico/ativo)

'João, ele foi visto' (impessoal/passivo) ${ }^{9}$

(GIVÓN, 2001, p. 22, tradução nossa).

Esse fato na história do quimbundo remete diretamente ao debate deriva/contato nos termos aqui propostos por:

(i) contrastar a convergência quanto aos procedimentos de adotar o modelo radial de categorização e o método diacrônico de análise com a divergência de separar gramática e léxico entre a linguística funcional e a linguística cognitiva;

(ii) apresentar um caso de deriva numa língua banta (o debate, em sua formulação tradicional, não leva em conta que derivas e contatos podem ter resultado nas variedades das línguas que entraram em contato como o português que viria ser brasileiro, sendo tais línguas idealizadas como isentas dos mesmos fatores considerados para a descrição do português brasileiro);

(iii) envolver a língua banta que, por contato, teria introduzido o deslocamento à esquerda no português que viria a ser brasileiro; e

(iv) suscitar a discussão sobre como uma teoria universalista pode compatibilizar o poder explicativo propiciado pela noção de contato com o poder explicativo propiciado pela noção de universais linguísticos a partir da identificação de uma propriedade compartilhada, vis-à-vis uma teoria relativista, para qual

9 Original: "L-dislocation plus impersonal 'they'

Finally, in some languages, such as Kimbundu, a passive construction arose diachronically from, and still resembles structurally, a left-dislocation construction plus the impersonal pronoun 'they', as in (Givón 1995: Ch. 3):

(24) a. Passive

Nzua a-mu-mono kwa meme

John they-him-saw by me

'John was seen by me'

(lit.: 'John, they saw him by me')

b. L-dislocation

Nzua, aana a-mu-mono

John children they-him-saw

'John, the children saw him'

c. Impersonal-subject with L-dislocation

Nzua, a-mu-mono

John they-him-saw

'John, they saw him' (anaphoric/active)

'John, he was seen' (impersonal/passive)” (GIVÓN, 2001, p. 22). 
“(...) cada língua tem uma forma interna privativamente sua. Distingue-se das demais pelo grupo de categorias que encerra, e pelos traços peculiares que matizam cada uma das categorias aparentemente comuns a mais outra ou outras línguas" (CÂMARA Jr., 1989, p. 126).

Em outras palavras, não é preciso ir tão longe quanto ao deslocamento à esquerda. Com base nessa versão de relativismo, predominante na história da linguística, as categorias gramaticais são aparentemente comuns por estarem a serviço da "[...] visão do universo (al. Weltansicht) ali consubstanciada [...]" (CÂMARA Jr., 1989, p. 116). $\mathrm{Na}$ leitura cognitivista defendida neste artigo, aparentemente comuns por estarem a serviço de diferentes cognições, de diferentes formas de vida.

Mantido o foco em construções como o deslocamento à esquerda no quimbundo e no português brasileiro, o compromisso com qualquer teoria relativista já leva a investigar essa construção em cada língua como privativamente sua e a rastreá-la diacronicamente. Com isso, a evolução do deslocamento à esquerda para a construção passiva no quimbundo torna a passiva daquela língua incomensurável com a passiva de qualquer outra e ilustra um caso de deriva, confirmando a afinidade original entre deriva e relativismo.

A tendência a descrever estruturas do português brasileiro com base no contato com línguas bantas supera o equívoco original de supor que o contato gera apenas empréstimos. No entanto, o compromisso com o modelo clássico de categorização, com o modelo modular de cognição e com o universalismo leva a uma investigação sobre o papel do contato que permite identificar produtos compartilhados. A pergunta que surge é se o português brasileiro e aquelas línguas bantas já não poderiam exibir algumas propriedades gramaticais em comum a despeito do contato, exatamente como mais de uma língua exibe construção passiva. $\mathrm{O}$ universalismo acaba enfraquecendo o poder explicativo das descrições.

Para Avelar e Galves (2014, p. 243-244),

[...] certas marcas gramaticais singularizadoras do português brasileiro no conjunto das línguas românicas se devem à ação dos contatos interlinguísticos estabelecidos entre falantes de português e de línguas africanas (em particular, línguas bantas). O que estamos chamando de ação indica, em linhas gerais, duas situações diferentes: (a) transferência de padrões frásicos e propriedades morfossintáticas das línguas africanas para o português adquirido como segunda língua pelos africanos e (b) propriedades desencadeadas por dificuldades em reproduzir, por parte dos africanos, as marcas da língua tomada como alvo (no caso, o português) quando da sua aquisição.

Convergimos quanto a certas marcas singularizadoras do português brasileiro se deverem ao contato entre falantes de português e falantes de línguas bantas. Apenas 
enfatizo que falantes são sujeitos cognoscentes, conceptualizadores. A tendência ao não preenchimento do argumento interno (objeto nulo) pode ser considerada uma dessas marcas (BEARTH, 2003).

A propósito, as próprias influências do contato no léxico se inserem entre tais marcas, uma vez que a superação da dicotomia entre léxico e gramática não implica o deslocamento do interesse do léxico para a gramática (MAGALHÃES, 2018). O que se dá é uma radical revisão da influência lexical: de marginal porque o léxico seria externo à gramática a central porque o léxico e a gramática são integrados pela submissão aos mesmos processos de domínio geral.

As implicações do contato sobre "[...] a aquisição do português como segunda língua, em condições de dominação [...]" (PAGOTTO, 2007, p. 476), consistem no ponto central da convergência, só que, em vez de me remeter a produtos compartilhados, apontam para as condições cognitivas para a aquisição de segunda língua nos diferentes tipos de colonização (MUFWENE, 2010). Assim, meu enfoque relativista privilegia uma agenda de investigação não coberta pela árdua porém insuficiente identificação de propriedades gramaticais compartilhadas, uma agenda que reconheça a variação como um fenômeno cognitivo, capaz de mapear conceptualizações (FABISZAK; HEBDA, 2011), perspectivizações (BATORÉO; FERRARI, 2015; MAGALHÃES, 2018), categorizações (LAKOFF, 1987; LANGACKER, 1987, 2008; BYBEE, 2010) e as próprias condições de dominação com o suporte interdisciplinar da história (SLENES, 1992, 1995, 2018; ALMEIDA, 2014, 2019).

No entanto, divergimos quanto ao alcance de uma abordagem universalista ao contato, seja porque o quadro teórico, a linguística gerativa, prevê que línguas diferentes possam fixar o mesmo valor para o mesmo parâmetro, seja porque a pesquisa em história (ALMEIDA, 2014) demonstra que certos contatos nunca existiram, como o supostamente havido entre o zulu e o português. O contato jamais ter se dado é, por sua vez, uma evidência cognitivista: para os universalistas, de que princípios e parâmetros são universais, cada língua é um feixe de diferentes valores, duas línguas que nunca entraram em contato podem exibir o mesmo valor para certo parâmetro; para os relativistas, de que cada língua encerra uma visão do universo, duas línguas que nunca entraram em contato podem exibir construções aparentemente comuns, a suposta "transferência de padrões frásicos e propriedades morfossintáticas" decorre da compatibilização entre conceptualizações, dado que, como enfatiza Mufwene (2010, p. 359, tradução nossa), "a transferência não é inelutável"10.

Assim, o quadro relativista tanto preserva que haja propriedades idênticas entre línguas diferentes com ou sem contato quanto prevê que o contato entre falantes de línguas bantas chegados ao Brasil como escravos e falantes daquela variedade do português no Brasil promoveu a aproximação de formas de vida, capaz de motivar

10 Original: "transfer of sentence patterns and morphosyntactic properties [... ] transfer is not ineluctable" (MUFWENE, 2010, p. 359). 
influência linguística, não de prever. Por isso, entendo que o que entra em contato não são línguas, e sim cognições.

Câmara Jr. (1989, p. 102), na sua clássica discussão sobre a prefixação ser da ordem da derivação ou da composição, apresenta um exemplo de prefixo flexional:

Já noutras línguas o prefixo é o tipo usual de afixo flexional. Assim, nas línguas africanas do grupo bântu, é por prefixos que se assinala a classe do nome (cf. § 65) e concomitantemente o singular ou plural. Haja vista a própria palavra bantu "homens", onde-ntué o semantema (que nunca aparece isolado) e $b a$ - o pref. pl. da classe pessoal, em oposição ao pref. sing. mu- de muntu "um homem" (cf. § 65).

O exemplo serve de excelente contraponto ao suposto contato com o zulu. Apesar de ter havido o contato do português com línguas bantas, o que viria a ser o que hoje se entende por português brasileiro não apresenta prefixo flexional. Esse dado estrutural, no entanto, não leva a negar a influência do contato na gramática.

Realmente, a transferência não é inelutável. Nos termos propostos neste artigo, ela é licenciada pela compatibilização entre conceptualizações distribuídas nas cognições em contato.

Bybee (2010), por sua vez, se dispõe a explicar o fato de línguas que não pertencem à mesma família exibirem o mesmo padrão de gramaticalização em que uma construção de futuro (tempo) emerge de uma construção de movimento (espaço). A autora retoma um estudo seu de 1994, em que analisou uma amostra de 76 línguas. Os passos da gramaticalização revistos à luz de processos de domínio geral permitem entender semelhanças entre línguas não aparentadas sem recorrer ao contato: à linguística funcional pela atenção a universais discursivo-textuais (KATO, 1998) ou a "fatores sociais que moldam a gramática" (BYBEE, 2010); à linguística cognitiva pela conciliação entre o caráter universal dos processos cognitivos e o relativismo caracterizado como sobreposição entre língua, cultura e pensamento acima (LANGACKER, 1994; CASASANTO, 2013).

A centralidade da conceptualização na linguística cognitiva se deve à concepção de significado, não somente como enciclopédico, mas também como perspectivista, conforme apontado acima.

Embora seja um fenômeno mental, a conceptualização é ancorada na realidade física: consiste em atividade do cérebro, que funciona como uma parte integrante do corpo, que funciona como uma parte integrante do mundo. Significados linguísticos também são ancorados em interação social, sendo negociados por interlocutores com base na avaliação mútua de seus conhecimentos, pensamentos e intenções. Como objeto de análise, a conceptualização é esquiva e desafiadora, mas não misteriosa 
ou além do escopo da investigação científica. ${ }^{11}$ (LANGACKER, 2008, p. 4, tradução nossa).

Se a negociação entre interlocutores remete à dimensão distribuída da cognição na condição de falantes da mesma língua, torna-se ainda mais relevante entre interlocutores que concebem o mundo diferentemente porque falam línguas diferentes. É nesse sentido que a dissolução da dicotomia entre deriva e contato abre um caminho de investigação científica acerca da conceptualização capaz de caracterizar uma linguística cognitiva de contato, dedicada exatamente à exploração do contato entre cognições, não em interação social simétrica sincronicamente observável, e sim em interação social assimétrica diacronicamente reconstruível a partir de dados escassos.

Já a categorização, desde a descrição do dyirbal em Lakoff (1987), revela que mulheres, fogo e coisas perigosas podem estar juntos sem que haja nada em comum, diferentemente do que prevê o modelo clássico. Quando o autor separa os falantes daquela língua entre mais novos e mais velhos, retoma o encadeamento e os domínios experienciais, dois dos princípios organizadores da categorização radial para a gramática das construções cognitiva, como os que atuam no estabelecimento de novas relações cognitivas entre a experiência e a formação de categorias. Nesses termos, a mudança linguística é um epifenômeno em relação à mudança nos princípios organizadores da categorização.

Neste artigo, tais princípios ganham especial importância por permitirem uma definição cognitivamente motivada do que seria deriva, já que Lakoff (1987) caracteriza aquele quadro de mudança e posterior morte do dyirbal como resultado da perda de relações encadeadoras (chaining links) de uma geração para outra, sem a participação do contato. Revista do ângulo proposto neste artigo, aquela descrição poderia ser situada na esfera da deriva tal como governada por um processo de domínio geral.

Novamente, como na evolução da construção de deslocamento à esquerda na construção passiva descrita por Givón (2001), deriva sem contato. Ou sem a identificação de contato(s)? Bastante diferente foi a história do português brasileiro.

A perspectivização, por sua vez, permite rastrear as crenças e atitudes das cognições que se compatibilizaram na configuração do português brasileiro. A linguística cognitiva considera a perspectiva como pré-requisito da conceptualização, o que leva de volta ao primeiro item na agenda de pesquisa aqui proposta.

11 Original: "Though it is a mental phenomenon, conceptualization is grounded in physical reality: it consists in activity of the brain, which functions as an integral part of the body, which functions as an integral part of the world. Linguistic meanings are also grounded in social interaction, being negotiated by interlocutors based on mutual assessment of their knowledge, thoughts, and intentions. As a target of analysis, conceptualization is elusive and challenging, but it is not mysterious or beyond the scope of scientific inquiry" (LANGACKER, 2008, p. 4). 


\section{Considerações finais}

Este artigo procurou demonstrar que deriva e contato necessariamente se imbricam quando há contato, uma vez substituídas dicotomias compartilhadas até mesmo entre teorias que se refutam, como léxico / gramática e história interna / história externa. Para tanto, localizou no debate sobre o papel da deriva ou do contato na história do português brasileiro pressupostos que merecem reflexão.

Um pressuposto foi que o reconhecimento do papel do contato implicaria o reconhecimento da ocorrência de crioulização. Tanto a partir de literatura que rejeita a dicotomia entre história interna e história externa quanto a partir da que define os fundamentos da linguística cognitiva, defendo a dissociação entre contato e crioulização, seja por sequer ser um processo linguístico, seja por ser, na melhor das hipóteses, um processo de domínio específico.

Outro pressuposto foi que o contato promoveria apenas influência lexical. Tal pressuposto, por sua vez, embute outro: que léxico e gramática são apartados. Afastada a dicotomia entre léxico e gramática, a influência do contato passa a incidir sobre a língua, não apenas a um de seus componentes, e a própria influência lexical assume outro status epistemológico.

Porque a influência do contato vem sendo reconhecida por estudos que preservam o modelo clássico de categorização, o artigo teve de remeter ao universalismo, em que tal modelo repousa, em contraste com o relativismo, em que se baseia o modelo radial. Isso porque a convergência quanto à influência do contato sobre a gramática não basta para explicar por que línguas que entraram em contato não transferiram certos padrões morfossintáticos nem por que os mesmos padrões morfossintáticos existem em línguas que não entraram em contato.

O passo seguinte foi propor que o contato se estabelece entre cognições, não entre línguas, o que exige migrar da esfera dos produtos (as línguas) para a esfera dos processos, especialmente os de domínio geral. Exige, por consequência, identificar quais são os processos propostos por cada modelo da linguística cognitiva e testar seu alcance explicativo numa agenda de pesquisa.

Os padrões latentes herdados da língua em sua configuração anterior necessariamente sofreram a interferência dos sucessivos contatos promovidos pelo tráfico de africanos escravizados ao longo de séculos. Logo, nem o contato nem a escravidão podem ser tratados como eventos homogêneos. A reconhecida necessidade de suporte da história exigirá refinamentos e delimitações que lancem mais luz sobre um fenômeno que se desenvolveu do século XVI ao XIX com feições específicas em cada momento, inclusive no que diz respeito aos contingentes populacionais deslocados, aos pontos de chegada no território brasileiro e às línguas que cada contingente trouxe.

Este artigo se insere numa agenda que se ocupa dessas questões a partir do olhar da linguística, em geral, e da linguística cognitiva, em particular. O quadro teórico tem, em suas bases, o compromisso com a dissolução de dicotomias erguidas com base em outros pressupostos, num arranjo de cartas em que basta empurrar a primeira para 
que todas as outras caiam. Aqui, as cartas universalismo, categorização aristotélica e modularidade cedem espaço às cartas relativismo (um compromisso da linguística anterior à linguística cognitiva), categorização radial (uma proposição obscurecida pelo rótulo sociolinguística e compartilhada por diferentes teorias) e conexionismo, de modo a derrubar mais uma dicotomia incompatível com o quadro teórico: a que separa, em vez de harmonizar, deriva e contato.

Alguns esclarecimentos se fizeram necessários. Primeiro, que se trata de dissolver a dicotomia deriva/contato mais que endossar a relevância do contato preservando a polarização. Segundo, que a própria definição de deriva tem caráter relativista. Terceiro, que o modelo da linguística cognitiva chamado gramática das construções cognitiva enfoca princípios organizadores da categorização radial e os aplica à mudança linguística, tratada como o que pode ser definido como fruto da deriva, enquanto o modelo chamado gramática cognitiva considera a categorização como um dos processos de domínio geral. Com isso, a teoria articula princípios que organizam a categorização com processos de domínio geral, dentre os quais a própria categorização.

Esse processo, concebido como radial por todos os modelos da linguística cognitiva, e os demais processos de domínio geral me parecem ser a chave para uma abordagem relativista das relações entre língua, cultura e cognição. Com base nessa chave é que me parecem viáveis uma linguística cognitiva de contato e uma sociolinguística cognitiva.

\section{Agradecimentos}

Meus especiais agradecimentos a Maria Lucia Leitão de Almeida (Universidade Federal do Rio de Janeiro) pela provocação a pensar em contato e as ótimas conversas sobre o tema; a Marcos Leitão de Almeida (Northwestern University) pela leitura atenta da primeira e da quase última versão deste artigo, as sugestões e o compartilhamento de um artigo ainda inédito; e a Anderson Salvaterra Magalhães (Universidade Federal de São Paulo) pelas leituras e as sugestões igualmente atentas.

LEMOS DE SOUZA, J. The drift/contact debate in the history of brazilian portuguese. Alfa, São Paulo, v.64, 2020.

- ABSTRACT: This paper resumes the debate over the prevalence of the drift factor, considered as strictly internal, or the contact factor, considered as strictly external in the constitution of Brazilian Portuguese. On the empirical level, it focuses on the contact with Bantu languages. On the theoretical level, the resumption favors the epistemological bases of cognitive linguistics, where the adequacy of two new branches is under discussion: a cognitive contact linguistics and a cognitive sociolinguistics. This paper recapitulates the association between contact and creolization in order to dissociate them; it rejects the thesis that contact is restrict to lexical influence, with a view to associating the drift/contact dichotomy to the lexicon/ 
grammar dichotomy; and it proposes a contact hypothesis based on domain-general processes. Reformulating the debate in these terms leads to the conclusion that contact motivates compatibilization among conceptualizations, for the matter being of cognition contact, not language contact.

- KEYWORDS: Cognitive Linguistics. Cognitive Contact Linguistics. Cognitive Sociolinguistics. Contact. Drift. Relativism. History of Brazilian Portuguese.

\section{REFERÊNCIAS}

ALMEIDA, M. A. L de. African voices from the Congo coast: speech communities, meanings and the process of identification in the slave ship Jovem Maria (1850). Journal of African History, Cambridge, p. 167-189, 2019.

ALMEIDA, M. A. L de. Vozes centro-africanas no Atlântico-Sul (1831-c.1850). In: LIMA, I. S.; CARMO, L. do (ed.). História social da língua nacional 2: diáspora africana. Rio de Janeiro: Nau Editora, 2014. p. 73-104.

ALMEIDA, M. L. L. de. A lingüística sociocognitiva e os anguladores: uma nova perspectiva para fenômenos tidos como marginais. In: HENRIQUES, C. C.; SIMÕES, D.; VALENTE, A. (org.). Língua portuguesa: reflexões sobre descrição, pesquisa e ensino. Rio de Janeiro: Europa, 2005. p. 56-67.

AVELAR, J. Sobre o papel do contato linguístico nas origens do português brasileiro. In: GALVES, C.; KATO, M.; ROBERTS, I. (org.). Português brasileiro: uma segunda viagem diacrônica. Campinas: Ed. da UNICAMP, 2019. p. 57-92.

AVELAR, J.; GALVES, C. O papel das línguas africanas na emergência da gramática do português brasileiro. Linguística: Revista da ALFAL, [s.1.], v. 30, n. 2, p. 241-288, 2014.

BATORÉO, H.; FERRARI, L. Quão fundo é o fundo? Perspectivação no caso das expressões com "ao fundo" em português europeu e português do Brasil. Estudos Linguísticos, Lisboa, v. 10, 2015.

BEARTH, T. Syntax. In: NURSE, D.; PHILIPSSON, G. (ed.). The Bantu languages. London: Routledge, 2003. p.121-142.

BYBEE, J. Language, usage, and cognition. Cambridge: Cambridge University Press, 2010.

CÂMARA Jr., J. M. Princípios de linguística geral. 7. ed. Rio de Janeiro: Padrão, 1989. Original de 1941.

CÂMARA Jr., J. M. Dicionário de lingüística e gramática. 13. ed. Petrópolis: Vozes, 1986. Original de 1977. 
CARDOSO, W.; CUNHA, C. Estilística e gramática histórica: português através de textos. Rio de Janeiro: Tempo Brasileiro, 1978.

CASASANTO, D. The role of language in metaphor. In: BORKENT, M.; DANCYGIER, B.; HINNELL, J. (ed.). Language and the creative mind: new directions in cognitive linguistics. Cambridge: Cambridge University Press, 2013. p. 3-18.

CROFT, W.; CRUSE, A. Cognitive linguistics. Cambridge: Cambridge University Press, 2004.

FABISZAK, M.; HEBDA, A. Cognitive historical approaches to emotions: pride. In: WINTERS, M.; TISSARI, H.; ALLAN, K. (ed.). Cognitive linguistics research. Berlin: Boston: Mouton De Gruter, 2011. p. 261-297.

FILLMORE, C. Scenes-and-frames semantics. In: ZAMPOLLI, A. (ed.). Linguistic structures processing. Amsterdam: New York: Oxford: North-Holland Publishing Company, 1977. p. 55-81.

FIORIN, J. L; PETTER, M. (org.). África no Brasil: a formação da língua portuguesa. São Paulo: Contexto, 2008.

FRANÇA, A. I; FERRARI, L.; MAIA, M. A linguística no século XXI: convergências e divergências no estudo da linguagem. São Paulo: Contexto, 2016.

GALVES, C. Princípios, parâmetros e aquisição da linguagem. Cadernos de Estudos Linguísticos, Campinas, n. 29, 1995.

GEERAERTS, D. Prospects for the past: perspectives for cognitive diachronic semantics. In: WINTERS, M.; TISSARI, H.; ALLAN, K. (ed.). Cognitive linguistics research. Berlin: Boston: Mouton De Gruter, 2011. p. 333-356.

GIVÓN, T. Syntax: an introduction. Amsterdam: Philadelphia: John Benjamins, 2001. v.1. Original de 1984.

GLOCK, H-J. Dicionário Wittgenstein. Tradução: Helena Martins. Revisão técnica: Luiz Carlos Pereira. Rio de Janeiro: Jorge Zahar, 1998.

KATO, M. Formas de funcionalismo na sintaxe. DELTA, São Paulo, v. 14, n. esp., 1998.

LAKOFF, G. Women, fire, and dangerous things: what categories reveal about the mind. Chicago: The University of Chicago Press, 1987.

LANGACKER, R. Investigations in cognitive grammar. Berlin: New York: Walter de Gruyter, 2009. (Cognitive linguistics research, 42).

LANGACKER, R. Cognitive grammar: a basic introduction. Oxford: Nova York: Oxford University Press, 2008. 
LANGACKER, R. Culture, cognition, and grammar. In: PÜTZ, M. (ed.). Language contact and language conflict. Amsterdam: Philadelphia: John Benjamins, 1994. p. 25-54.

LANGACKER, R. Foundations of cognitive grammar: theoretical prerequisites. Stanford: Stanford University Press, 1987. v.1.

LEMOS DE SOUZA, J. Fundamentos epistemológicos da linguística cognitiva. In: ÁLVARO, P.; FERRARI, L. (org.). Linguística cognitiva: da linguagem aos bastidores da mente. Rio de Janeiro: Brasil Multicultural, 2016. p. 2-23.

LUCCHESI, D. A língua mina-jeje no Brasil: um falar africano em Ouro Preto do século XVIII. DELTA, São Paulo, v. 20, n. 1, 2004.

MAGALHÃES, A. Pejoração e constituição do léxico brasileiro: um estudo semântico acerca de bantuísmos na interface da análise dialógica do discurso e da linguística cognitiva. 142f. 2018. Relatório de pesquisa (Pós-Doutorado em Língua Portuguesa) Universidade Federal do Rio de Janeiro, Rio de Janeiro, 2018.

MARTINS, H. Três caminhos na filosofia da linguagem. In: MUSSALIM, F.; BENTES; A. (org.). Introdução à linguística: fundamentos epistemológicos. 5. ed. São Paulo: Cortez, 2011. v.3. p. 439-473.

MARTINS, H. Metáfora e polissemia no estudo das línguas do mundo: uma apresentação não-representacionista. Orientação: Margarida Basilio. 190f. 1999. Tese (Doutorado em Linguística) - Universidade Federal do Rio de Janeiro, Rio de Janeiro, 1999.

MUFWENE, S. The emergence of creoles and language change. In: BONVILLAIN, N. (ed.). The Handbook of Linguistic Anthropology. London: Routledge, 2015. p. 345-368.

MUFWENE, S. SLA and the emergence of creoles. Studies in Second Language Acquisition, Cambridge, v.32, p. 359-400, 2010.

MUFWENE, S. Population movements and contacts in language evolution. Journal of Language Contact, Leiden, v.1, p. 63-91, 2007.

MUFWENE, S. Creolization is a social, not a structural, process. In: NEUMANNHOLZSCHUH, I.; SCHNEIDER, E. (ed.). Degrees of restructuring in creole languages. Amsterdam: Philadelphia: John Benjamins, 2000. p. 65-83.

NARO, A.; SCHERRE, M. Origens do português brasileiro. São Paulo: Parábola, 2007.

NEGRÃO, E.; VIOTTI, E. Contato entre quimbundo e português clássico: impactos na gramática de impessoalização do português brasileiro e angolano. Lingüística, Montevideo, v. 30, 2014. 
NEGRÃO, E.; VIOTTI, E. Em busca de uma história linguística. Revista de Estudos Linguísticos, Belo Horizonte, v. 20, n. 2, 2012.

NOËL, D. Cognitive contact linguistics as an essential ingredient of diachronic construction grammar. In: INTERNATIONAL COGNITIVE LINGUISTICS CONFERENCE (ICLC-13), 13., Newcastle. Proceedings [...],Newcastle: Northumbria University, 20-25 jul. 2015. Disponível em: https://core.ac.uk/download/pdf/38074502. pdf. Acesso em: 23 jul. 2020.

NURSE, D.; PHILIPPSON, G. (ed.). The Bantu languages. London: Routledge, 2003.

OLIVEIRA, K.; LOBO, T. Introdução: ou sobre como a África, no Brasil, avista a escrita. In: LOBO, T.; OLIVEIRA, K. (org.). África à vista: dez estudos sobre o português escrito por africanos no Brasil do século XIX. Salvador: EdUFBA, 2009. p. 6-49.

OLIVEIRA, K.; SOLEDADE, J.; SANTOS, V. de S. Concordância nominal. In: LOBO, T.; OLIVEIRA, K. (org.). África à vista: dez estudos sobre o português escrito por africanos no Brasil do século XIX. Salvador: EdUFBA, 2009. p. 255-316.

PAGOTTO, E. Crioulo sim, crioulo não: uma agenda de problemas. In: CASTILHO, A. de; MORAIS, M. A.; LOPES, R.; CYRINO, S. (org.). Descrição, história e aquisição do português brasileiro. São Paulo: FAPESP; Campinas: Pontes, 2007. p. 461-482.

PESSOA DE CASTRO, Y. Renato Mendonça e "A influência africana no português do Brasil”, um estudo pioneiro de africanias no português brasileiro. In: MENDONÇA, R. A influência africana no português do Brasil. Brasília: FUNAG, 2012. p. 15-28.

SALOMÃO, M. Teorias da linguagem: a perspectiva sociocognitiva. In: MIRANDA, N.; SALOMÃO, M. (org.). Construções do português do Brasil: da gramática ao discurso. Belo Horizonte: Ed. da UFMG, 2009. p. 20-32.

SAPIR, E. Language: an introduction to the study of speech. New York: Harcourt; Brace, 1921.

SLENES, R. Metaphors to live by in the diaspora: conceptual tropes and ontological wordplay among Central Africans in the middle passage and beyond. In: ALBAUGH, E.; DE LUNA, K. (org.). Tracing language movement in Africa. New York: Oxford University Press, 2018. p. 343-363.

SLENES, R. Malungu, Ngoma Vem!: África encoberta e descoberta no Brasil. Cadernos do Museu da Escravatura, Luanda, Angola, v. 1, p. 1-24, 1995.

SLENES, R. Malungu, Ngoma Vem!: África coberta e descoberta no Brasil. Revista USP, São Paulo, v. 12, p. 48-67, 1992. 
SOARES DA SILVA, A. A sociolinguística cognitiva: razões e escopo de uma nova área de investigação linguística. Revista Portuguesa de Humanidades: Estudos Literários, Braga, v.13, p.191-212, 2009.

SOARES DA SILVA, A. O mundo dos sentidos em português: polissemia, semântica e cognição. Coimbra: Almedina, 2006.

VIOTTI, E. Mudança linguística. In: FIORIN, J. L. (org.). Linguística?: Que é isso? São Paulo: Contexto, 2013. p. 137-180.

WEINRICH, U.; LABOV, W.; HERZOG, M. Empirical foundations for a theory of language change. In: LEHMANN, W.; MALKIEL, Y. (ed.). Directions for historical linguistics: a symposium. 3. ed. Austin: University of Texas Press, 1968. p. 95-195.

ZENNER, E. Cognitive contact linguistics: the macro, meso and micro influence of English on Dutch. Orientação: Dirk Geeraerts. Co-orientação: Dirk Speelman. 420f. 2013. Tese (Doutorado em Linguística) - Katholieke Universiteit Leuven, Leuven, 2013.

ZENNER, E.; BACKUS, A.; WINTER-FROEMEL, E. (ed.). Cognitive contact linguistics: placing usage, meaning and mind at the core of contact-induced variation and change. Berlin: Boston: De Gruyter Mouton, 2018.

Recebido em 21 de julho de 2018

Aprovado em 11 de maio de 2019 